\title{
Perencanaan Pembangkit Listrik Tenaga Surya Di Pos Pengamatan Gunung Soputan
}

\author{
Sigit Sumakajati ${ }^{1}$; Novi Gusti Pahiyanti ${ }^{2}$; Axl Brian Androcles Tangkilisan ${ }^{3}$ \\ ${ }^{1,2,3}$ Sekolah Tinggi Teknik PLN \\ ${ }^{1}$ sigit.sukmajati@sttpln.ac.id \\ ${ }^{2}$ novi.gusti@sttpln.ac.id (corresponding authors) \\ 3axlbrian93@yahoo.com
}

\begin{abstract}
This planning is carried out on the basis to meet the electricity needs that must continuously deliver electricity at the observation point of Mount Soputan, this is because electricity needs are very important in seeing the movement of the volcano. This plan with a planned load of $18.04 \mathrm{kWh}$. For such loading, 20 solar panels with $200 \mathrm{Wp}$ capacity are used, and 2 solar panels controllers (SCC) are used, with each SCC used for 10 solar panels. As for the batteries used as many as 3 pieces with each battery having an energy of $2.4 \mathrm{kWh}$, then for the inverter using an inverter with a power of $2650 \mathrm{~W}$.
\end{abstract}

Keywords: Volcano, Planning, Solar Power Plant

\section{ABSTRAK}

Perencanaan ini dilakukan atas dasar untuk memenuhi kebutuhan listrik yang harus secara terus menerus menyalurkan listrik pada pos pengamatan gunung Soputan, hal ini dikarenakan kebutuhan listrik sangat penting dalam melihat pergerakan dari Gunung berapi tersebut. Perencanaan ini besar beban yang direncanakan sebesar 18,04 kWh. Untuk pembebanan yang demikian maka digunakan panel surya sebanyak 20 panel dengan kapasitas $200 \mathrm{Wp}$, dan untuk solar charger controller (SCC) yang digunakan sebanyak 2 buah dengan masing-masing SCC digunakan untuk 10 panel surya. Sedangkan untuk baterai yang digunakan sebanyak 3 buah dengan masing-masing baterai memiliki energi sebesar 2,4 kWh, lalu untuk inverternya menggunakan inverter dengan daya sebesar $2650 \mathrm{~W}$.

Kata kunci: Gunung Api, Perencanaan, PLTS 


\section{PENDAHULUAN}

Indonesia merupakan negara berkembang yang masih membutuhkan sistem kelistrikan yang optimal, berbagai daerah-daerah yang ada diindonesia masih belum terpenuhi dan masih belum diterangi oleh pihak PLN, terutama didaerah terpencil seperti pedesaan dan lainnyaa. Begitu banyak kendala yang dihadapi dari pihak penyedia listrik (PLN) terutama masalah tempat yang begitu jauh dan medan yang sulit dalam masalah transmisi. Pemerintah pun masih belom memberikan bantuan yang semestinya dalam menerangi pelosok-pelosok negeri. Ada bagian-bagian dalam sistem diindonesia yang sangat perlu diberikan pasokan listrik karena ini bergantung dengan bencana alam yang tidak disebabkan oleh campur tangan manusia, yaitu untuk Pos Pengamatan Gunung Berapi. Pengamatan gunung berapi tidak boleh disampingkan, karena ini menyangkut dengan bencana alam yang tidak tau kapan akan terjadi, apalagi jika gunung berapi tersebut dikatakan dalam keadaan waspada, siaga dan lain sebagainya. Oleh karena itu perlu upaya-upaya yang bagus dalam menanggapi hal ini, yaitu adanya pasokan listrik yang sangat optimal setiap harinya, bahkan setiap jamnya. Karena pengamatan perlu dilakukan 24 jam non stop. Upaya Ini sangat baik dilakukan jika menggunakan pembangkit listrik tenaga surya, karena pembangkit ini tidak bergantung dengan musim tapi bergantung dengan penyinaran matahari. Pemanfaatan cahaya matahari ini juga tergolong masih belum banyak diIndonesia karena masih mengoptimalkan penggunaan pembangkit deasel, PLTU, PLTG dan sebagainya. Tapi tidak menutup kemungkinan akan habis dengan sendirinya karena bergantung pada bahan bakar yang tidak bisa diperbaharui. Indonesia termasuk Negara yang memiliki suhu yg optimal dan mendapat penyinaran dari sinar matahari yg tergolong lama yaitu kurang lebih 12 jam. Jadi sangat disayangkan jika tidak memanfaatkan sinar matahari secara optimal untuk menghasilkan listrik. Tapi dalam penerapannya cukup sulit untuk membangun PLTS dikarenakan investasi yang cukup besar dan perlu tahap-tahap perizinan yang sangat banyak. Dalam arti yang luas juga, sumber energi surya atau tenaga matahari bukan hanya terdiri atas pancaran matahari langsung ke bumi, melaikan juga melalui efek-efek matahari tidak langsung, seperti tenaga angin, tenaga air, panas laut, dan bahkan termasuk biomassa yang dapat memanfaatkan sebagai sumber energi.

Berapa besar jumlah energi yang dikeluarkan oleh matahari sukar dibayangkan. Menurut salah satu perkiraan, inti sang surya yang merupakan suatu tungku termonuklir bersuhu 100 juta derajat Celsius tiap detik mengkonversi 5 ton materi menjadi energy yang dipancarkan ke angkasa luas sebanyak $64.100 .000 \mathrm{~W} / \mathrm{m}^{2}$. sang surya merupakan suatu bintang yang istimewa. Ia mempunyai radius sebesar $69.600 .000 \mathrm{~km}$ dan terletak rata-rata sejauh $149.600 .000 \mathrm{~km}$ dari bumi (Energi edisi kedua:1995, chapter 15).

Adapun tujuan dipilihnya judul "Perencanaan Pembangkit Listrik Tenaga Surya di Pos Pengamatan Gunung Soputan" yaitu untuk mengetahui berapa besar kapasitas baterai yang terpasang, berapa banyak panel surya yang harus dipasang dalam perancangan pembangkit listrik tenaga surya untuk memenuhi kapasitas kelistrikan di Pos Pengamatan di Gunung Soputan.

\section{METODE/PERANCANGAN PENELITIAN}

\subsection{Analisa Kebutuhan}

Dalam penelitian ini kebutuhan yang diperlukan terdiri dari beberapa hal yaitu data yang di perlukan seperti halnya nilai iradian yang didapat dari NASA dengan memastikan nilai koordinatnya, kapasitas beban listrik yang dibutuhkan, berapa besar beban puncak yang harus di capai, berapa banyak panel surya, berapa besar kapasitas baterai yang akan dipakai, jumlah baterai, serta peralatan yang dibutuhkan dalam perancangan pembangkit listrik tenaga surya untuk memenuhi kebutuhan taman bacaan di desa tersebut. 


\section{KILAT}

Vol. 8, No. 2, Oktober 2019, P-ISSN 2089-1245, E-ISSN 2655-4925

\subsection{Perancangan Penelitian}

Perancangan penelitian untuk merancang sebuah pembangkit listrik tenaga surya yang akan dipasang pada Pos pengamatan Gunung Soputan dengan flowchart sebagai berikut :

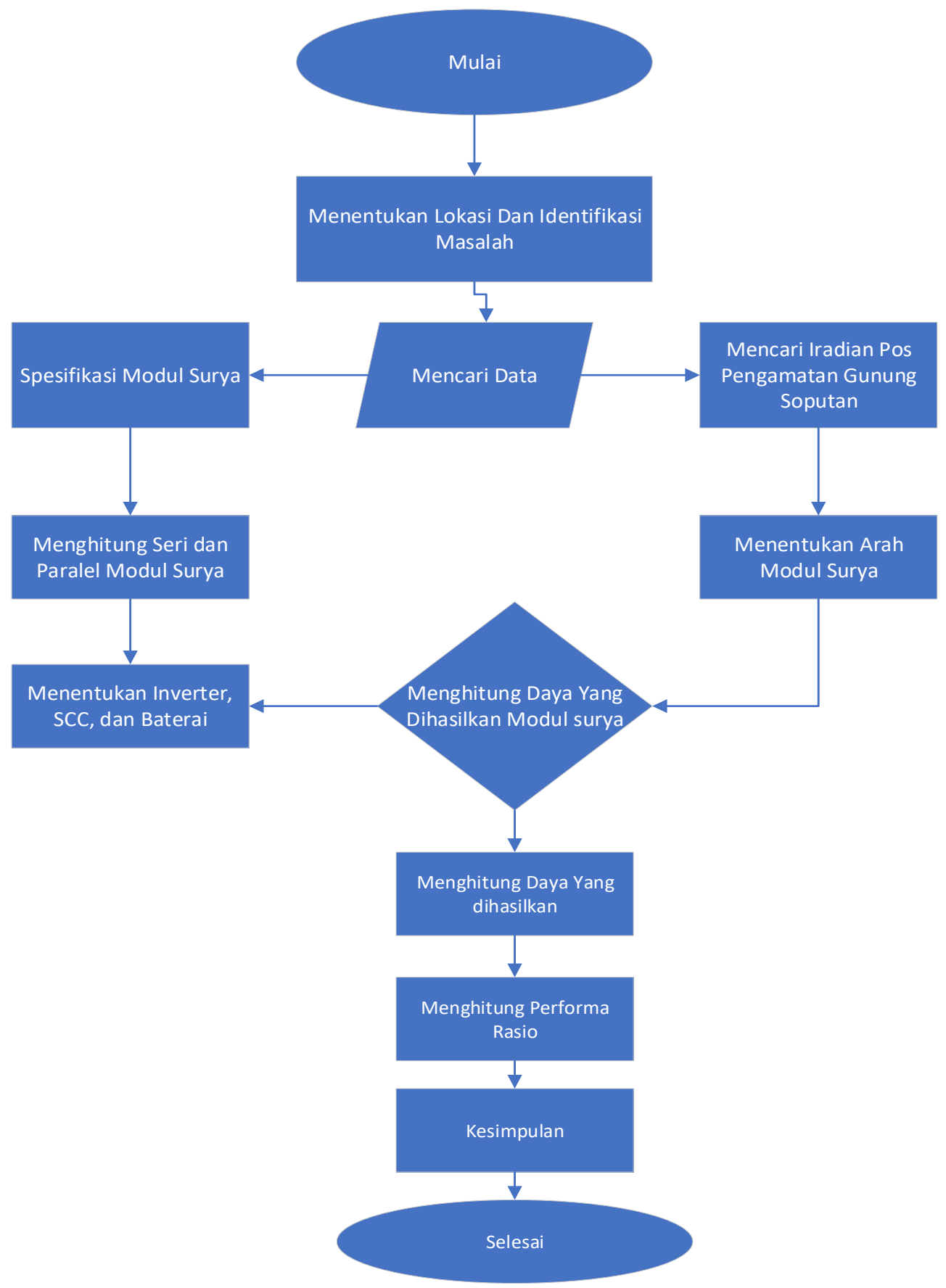

Gambar 1. Diagram Alir Perencanaan Pembangkit Listrik Tenaga Surya Di Pos Pengamatan Gunung Soputan

Berdasarkan diagram alir diatas dapat dijelaskan beberapa tahap yang dilakukan dalam Perencanaan penelitian ini sebagai berikut: 
1. Melakukan pencarian data mengenai nilai iradian yang didapatkan dari data NASA, sebagai berikut:

Tabel 1. Nilai Iradian Yang di dapatkan Dari Data Nasa

\begin{tabular}{|l|c|c|}
\hline \multicolumn{1}{|c|}{ Bulan } & Iradian $\left(\mathrm{Wp} / \mathrm{m}^{2}\right)$ & Temperatur $\left({ }^{\circ} \mathrm{C}\right)$ \\
\hline Januari & 5.43 & 30.32 \\
\hline Februari & 5.33 & 30.41 \\
\hline Maret & 5.85 & 31.13 \\
\hline April & 6.25 & 31.7 \\
\hline Mei & 6.13 & 31.28 \\
\hline Juni & 6.07 & 30.64 \\
\hline Juli & 6.14 & 30.21 \\
\hline Agustus & 6.45 & 30.99 \\
\hline September & 6.53 & 32.36 \\
\hline Oktober & 6.25 & 32.9 \\
\hline November & 6.07 & 31.85 \\
\hline Desember & 5.57 & 30.83 \\
\hline Rata - rata & 6.01 & 31.22 \\
\hline
\end{tabular}

2. Melakukan persiapan spesifikasi komponen pembangkit listrik tenaga surya yang akan dipasang seperti halnya :

a. Panel Surya jSky $200 \mathrm{Wp}$ Polycrystalline

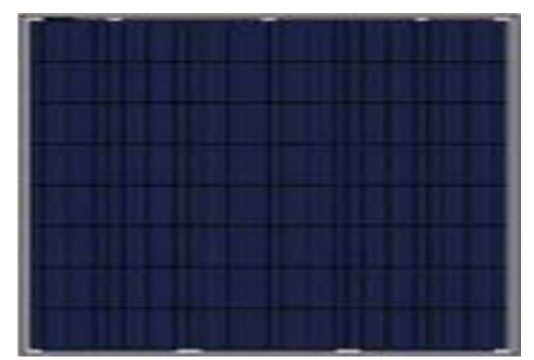

Gambar 2. Jsky Solar Panel 200 Wp

Tabel 2. Spesifikasi Panel Surya

\begin{tabular}{|c|l|c|}
\hline No & \multicolumn{1}{|c|}{ Spesifikasi } & Keterangan \\
\hline 1 & Power ( Pmax) & $200 \quad$ Watts \\
\hline 2 & Power Tolerance & $0 \sim+3 \%$ \\
\hline 3 & Open Circuit Voltage (Voc) & $29.8 \mathrm{~V}$ \\
\hline 4 & Short Circuit Current (Isc) & $8.73 \mathrm{~A}$ \\
\hline 5 & & \\
\hline 6 & Maximum Power Voltage ( Vmp ) & $24.6 \mathrm{~V}$ \\
\hline 7 & Maximum Power Current ( Imp ) & $8.14 \mathrm{~A}$ \\
\hline 8 & Efficiency & $360 \mathrm{~V}$ \\
\hline
\end{tabular}




\section{KILAT}

Vol. 8, No. 2, Oktober 2019, P-ISSN 2089-1245, E-ISSN 2655-4925

b. Pemilihan Inverter SMA Sunny Boy 2.5



Gambar 3. Inverter SMA Sunnyboy

c. Pemilihan Solar Charger controller Jenis MPPT

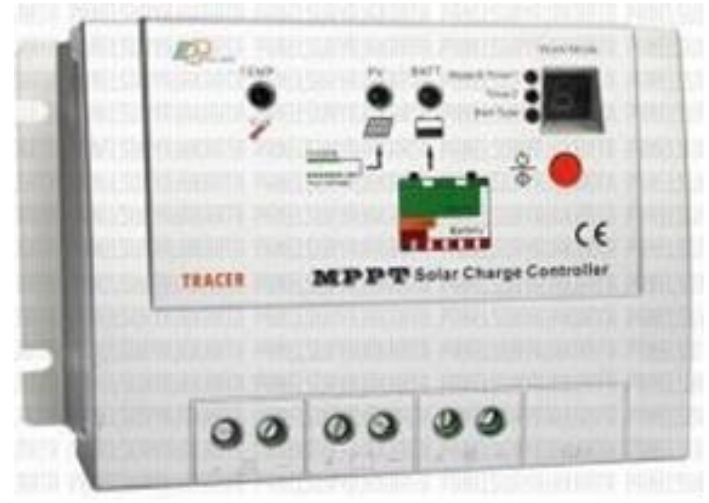

Gambar 4. Solar Charger Controller

Tabel 3. Spesifikasi Solar Charger Controller

\begin{tabular}{|c|c|}
\hline Spesifikasi & Keterangan \\
\hline Nominal System Voltage & $12 \mathrm{~V} / 24 \mathrm{~V}$ auto work \\
\hline Rated Battery Current & $20 \mathrm{~A}$ \\
\hline Rated Load Current & $20 \mathrm{~A}$ \\
\hline Maximum Battery Voltage & $32 \mathrm{~V}$ \\
\hline Max. Solar Input Voltage & $100 \mathrm{VDC}$ \\
\hline Max. PV Input Power & $12 \mathrm{~V} 260 \mathrm{~W}$ \\
\hline & $24 \mathrm{~V} \mathrm{520 \textrm {W }}$ \\
\hline Dimension $(\mathrm{mm})$ & $169 \times 118 \times 83$ \\
\hline Weight $(\mathrm{Kg})$ & 0.98 \\
\hline Enclosure & IP30 \\
\hline
\end{tabular}




\section{d. Baterai VRLA GEL 12V}

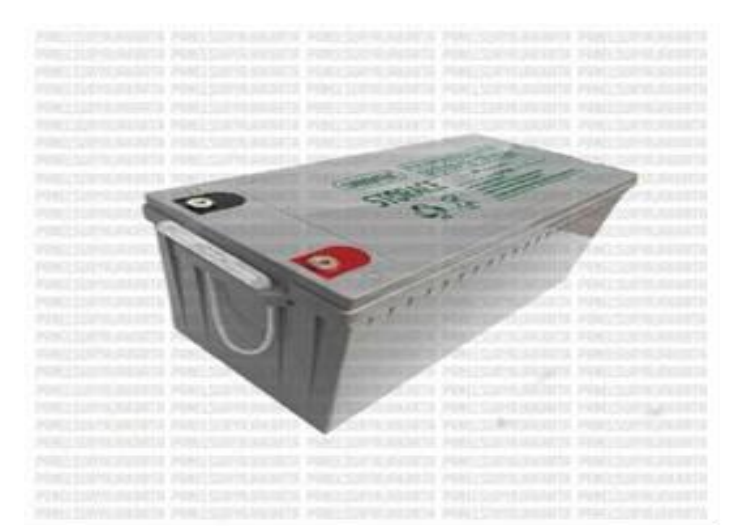

Gambar 5. Baterai VRLA GEL 12V 200Ah

Tabel 4. Spesifikasi Baterai VRLA GEL 12V 200Ah

\begin{tabular}{|c|c|c|}
\hline \multicolumn{2}{|c|}{ Spesifikasi } & Keterangan \\
\hline \multicolumn{2}{|c|}{ Nominal Voltage } & $12 \mathrm{~V}$ \\
\hline \multicolumn{2}{|c|}{ Rated Capacity (20HR) } & $200 \mathrm{Ah}$ \\
\hline \multirow{3}{*}{ Dimensions } & Length & $522 \mathrm{~mm}$ \\
\cline { 2 - 3 } & Width & $238 \mathrm{~mm}$ \\
\cline { 2 - 3 } & Height & $218 \mathrm{~mm}$ \\
\cline { 2 - 3 } & Total Heigth & $222 \mathrm{~mm}$ \\
\cline { 2 - 3 } & Approx. Mass & $59,0 \mathrm{~kg}$ \\
\hline
\end{tabular}

3. Melakukan pengecekan data beban yang dipakai di Pos Pengamatan Gunung Soputan

4. Menentukan kapasitas PV modul, pada saat menentukan kapasitas PV menggunakan rumus sebagai berikut:

$$
P V \text { Area }=\frac{E L}{\text { Gav } x \eta P V \times T C F \times \eta o u t}
$$

5. Menentukan Rangkaian Panel Surya, dalam menentukan rangkaian panel surya dapat dilakukan berdasarkan rumus dibawah ini:

SecaraSeri:Min Modul Seri Per String $=\frac{\text { Minimum System Voltage }}{\text { Maximum Power Voltage }(\text { Vmp })}$

Secara Paralel : Max Modul Seri Per String $=\frac{\text { Maximum System Voltage }}{\text { Open Circuit Voltage }(\text { Voc })}$

6. Menentukan Kapasitas Solar Charger Controller

7. Menentukan Kapasitas Baterai, dalam menentukan kapasitas baterai menggunakan perhitungan dengan rumus sebagai berikut:

Jumlah Baterai Seri $=\frac{\text { Tegangan } \text { kerjas Sistem }(\text { Vdc })}{\text { Tegangan Kerja Unit Baterai }}$ 


$$
\text { Jumlah Baterai Paralel }=\frac{\text { Kebutuhan Energi }}{\text { Teagangan Kerja Sistem } \times \text { Ah Baterai } x D O D}
$$

8. Menetukan kapasitas Inverter

\section{HASIL DAN PEMBAHASAN}

Pada penelitian mengenai perencenaan pembangkit litsrk tenaga surya di Pos Pengamatan Gunung Api Soputan memiliki hasil dalam pengecekan beban yang dipakai didapat hasil sebagai berikut:

Tabel 5. Data Beban Yang Dipakai Pada Pos Pengamatan Gunung Api Soputan

\begin{tabular}{|c|l|c|c|c|c|}
\hline No & \multicolumn{1}{|c|}{ Alat - alat Listrik } & Jumlah & $\begin{array}{c}\text { Lama } \\
\text { Pemakaian } \\
(\text { Jam })\end{array}$ & $\begin{array}{c}\text { Daya } \\
\text { (Watt) }\end{array}$ & $\begin{array}{c}\text { Total Energi/ } \\
\text { Hari (Wh) }\end{array}$ \\
\hline 1 & Lampu & 15 buah & 10 & 18 & 2700 \\
\hline 2 & $\begin{array}{l}\text { Komputer dan Komponen Pendukung } \\
\text { Lainnya }\end{array}$ & 1 buah & 24 & 400 & 9600 \\
\hline 3 & Discriminator & 1 buah & 24 & 46 & 1104 \\
\hline 4 & $\begin{array}{l}\text { Seismograf } \\
\text { (Drum } \\
\text { Recorder) }\end{array}$ & 1 buah & 24 & 10 & 240 \\
\hline 5 & Radio Box & 1 buah & 24 & 1 & 24 \\
\hline 6 & Modem Vsat & 2 buah & 24 & 5 & 240 \\
\hline 7 & Printer & 1 buah & 1 & 0,8 & 0,8 \\
\hline 8 & Televisi & 1 buah & 7 & 55 & 385 \\
\hline 9 & Pemanas Air & 1 buah & 6 & 350 & 2100 \\
\hline 10 & Pompa Air & 1 buah & 5 & 280 & 1400 \\
\hline 11 & $\begin{array}{l}\text { Keperluan Lain } \\
\text { (Charge Hp dll.) }\end{array}$ & & 5 & 50 & 250 \\
\hline \multicolumn{2}{|l|}{ Total } & & 1472,4 & $18,0438 \mathrm{KWh}$ \\
& & & Watt & \\
\hline
\end{tabular}

Berdasarkan hasil perhitungan yang dilakukan didapat beberapa parameter yang dapat mendukung perencanaan penelitian dalam merancang pembangkit listrik tenaga surya sebagai berikut: 
Tabel 6. Hasil Perhitungan Berdasarkan Metode Penelitian

\begin{tabular}{|c|c|c|c|c|c|c|c|c|c|}
\hline \multirow[b]{2}{*}{$\begin{array}{c}\text { Kapasit } \\
\text { as PV } \\
\text { Modul }\end{array}$} & \multicolumn{3}{|c|}{ Rangkaian Panel Surya } & \multirow{2}{*}{$\begin{array}{c}\text { Tegangan } \\
\text { Maksimu } \\
\mathrm{m}\end{array}$} & \multirow{2}{*}{$\begin{array}{c}\text { Arus } \\
\text { maksimu } \\
\mathrm{m}\end{array}$} & \multirow{2}{*}{$\begin{array}{l}\text { Kapasit } \\
\text { as Solar } \\
\text { Charger } \\
\text { Control }\end{array}$} & \multirow{2}{*}{$\begin{array}{l}\text { Jumlah } \\
\text { Baterai }\end{array}$} & \multirow{2}{*}{$\begin{array}{l}\text { Kapasit } \\
\text { as } \\
\text { Inverter }\end{array}$} & \multirow{2}{*}{$\begin{array}{c}\text { Daya } \\
\text { Keluara } \\
\text { n PLTS }\end{array}$} \\
\hline & $\begin{array}{l}\text { Secara } \\
\text { Seri } \\
\text { Minim } \\
\text { al }\end{array}$ & $\begin{array}{l}\text { Secara } \\
\text { Seri } \\
\text { Maksim } \\
\text { al }\end{array}$ & $\begin{array}{l}\text { Secar } \\
\text { a } \\
\text { Paral } \\
\text { el }\end{array}$ & & & & & & \\
\hline $\begin{array}{l}18,04 \\
\mathrm{~kW} \\
\text { dengan } \\
\text { Luas } \\
\text { Area } \\
\mathrm{PV} \\
\text { Sebesa } \\
\mathrm{r} \\
29,01 \\
\mathrm{~m}^{2}\end{array}$ & $\begin{array}{l}3 \\
\text { panel }\end{array}$ & $\begin{array}{l}12 \\
\text { panel }\end{array}$ & $\begin{array}{l}2 \\
\text { panel }\end{array}$ & $\begin{array}{l}\text { Seri } 240 \\
\text { Volt }\end{array}$ & $\begin{array}{l}\text { Paralel } \\
8,14 \text { A }\end{array}$ & 2 buah & $\begin{array}{l}2 \text { buah } \\
\text { (seri) } \\
3 \text { buah } \\
\text { (parale } \\
\text { 1) }\end{array}$ & $\begin{array}{l}600 \\
\text { volt } \\
10 \mathrm{~A} \\
\text { seri } \\
\text { tidak } \\
\text { lebih } \\
\text { dari } 12 \\
\text { dan } \\
\text { tidak } \\
\text { kurang } \\
\text { dari } 3\end{array}$ & $\begin{array}{l}3,4 \\
\mathrm{Kw}\end{array}$ \\
\hline
\end{tabular}

\section{KESIMPULAN DAN SARAN}

Setelah melakukan Perencanaan pembangkit listrik tenaga surya dihasilkan kesimpulan sebagai berikut bahwa dalam Perencanaan pembangkit ini dengan beban yang dipakai di Pos Pengamatan Gunung Api Soputan sebesar 18,04 kW, dengan daerah pemasangan PV seluas 29,01 $\mathrm{m}^{2}$, dengan jumlah PV sebanyak 20 buah panel surya, dengan SCC sebanyak 2 buah, serta jumlah baterai sebanyak 3 buah yang dipasang secara paralel, dengan kapasitas ineverter sebesar $2650 \mathrm{~W}$.

\section{UCAPAN TERIMAKASIH}

Penulis mengucapkan terima kasih kepada Desa Soputan yang telah memberikan keluangan waktunya khusunya pada Pos Pengamatan Gunung Api Soputan, Sekolah Tinggi Teknik PLN yang telah memberikan kesempatan untuk melakukan penelitian ini, dan telah memberi dukungan yang membantu pelaksanaan penelitian dan atau penulisan artikel.

\section{DAFTAR PUSTAKA}

[1] Datasheet PV Module, www.jSkysolar.co.id. Diunduh tanggal 1 Agustus 2019.

[2] Datasheet Inverter, www.sunnyboyinverter.co.id. Diunduh tanggal 1 Agustus 2019.

[3] Mojica, E. E., Ardaniel, A.-A. S., Leguid, J. G., \& Loyola, A. T. (2017). Development of a low-cost biogas filtration system to achieve higher-power efficient AC generator. In International Conference on Engineering and Technology (IntCET 2017) (Vol. 20042, pp. 17). https://doi.org/10.1063/1.5022936

[4] Nisa, T. C., Siregar, R. R. A., \& Suliyanti, W. N. (2019). Estimasi Daya Beban Listrik Pada Gardu Induk Cengkareng Dengan Menggunakan Metode TIME Series Model Dekomposisi. TEKNOLOGIA, 2(1).

[5] Muhammad Ibrahim A Arafa, El-Sayed Soliman Said. "An Optimized Design Criteria of NonOutage and Power Reduction for Hybrid Solar-Grid System (Residential Homes - Case Study)" Electrical Engineering Al-Azhar University, Nineteenth International Middle East Power Systems Conference (MEPCON), Menoufia University, Egypt, 19-21 December 2017 


\section{KILAT}

Vol. 8, No. 2, Oktober 2019, P-ISSN 2089-1245, E-ISSN 2655-4925

[6] Mohamad Sidik Boedoyo. "Potensi dan Peranan PLTS Sebagai Energi Alternatif Masa Depan di Indonesia, Jurnal Sains dan Teknologi Indonesia, Vol. 2 No.14, Agustus 2012

[7] Yu Hee Tan, Moh Isa Maryam. "Design of A Mini Solar Power System" Faculty Of Engineering, University Putra Malaysia, 43400, Selangor Malaysia, 2009

[8] Jurnal, R. (2018). Potensi Pemanfaatan Limbah Pembakaran Batubara (Bottom Ash) Pada Pltu Sebagai Media Tanam Dalam Upaya Mengurangi Pencemaran Lingkungan. Kilat, 7(1), 3646. Https://Doi.Org/10.33322/Kilat.V7i1.97

[9] Siregar RR, Wardana N. Luqman.“. Sistem Monitoring Kinerja Panel Listrik Tenaga Surya Menggunakan Arduino Uno.” JETri J. Ilm. Tek. Elektro. 2017;14(2):81-100.

[10] Handayani, O., Darmana, T., \& Widyastuti, C. (2019). Analisis Perbandingan Efisiensi Penyaluran Listrik Antara Penghantar ACSR dan ACCC pada Sistem Transmisi 150kV. Energi \& Kelistrikan, 11(1), 37 - 45. https://doi.org/10.33322/energi.v11i1.480

[11] Sukmajati, S., \& Hafidz, M. (2015). Perancangan Dan Analisis Pembangkit Listrik Tenaga Surya Kapasitas $10 \mathrm{Mw}$ On Grid Di Yogyakarta. Energi \& Kelistrikan, 7(1), 49-63. https://doi.org/10.33322/energi.v7i1.582

[12] Jurnal, R. (2018). Pemanfaatan Radiasi Energi Tegangan $150 \mathrm{Kv}$ Untuk Lampu Led Penerangan Jalan. KILAT, 7(1), 51-55.

[13] Yogianto, A., Hajar, I., \& Azzahra, S. (2018). Pemodelan Pembangkit Listrik Fotovoltaik Yang Terhubung Ke Jaringan. KILAT, 7(2), 201-209. https://doi.org/10.33322/kilat.v7i2.363

[14] Jurnal, R. (2019). Karakteristik Pemakaian Tenaga Surya Pada Modul Solar Smart Sebagai Implementasi Dari Listrik Kerakyatan. Energi \& Kelistrikan, 10(1), 15-19. https://doi.org/10.33322/energi.v10i1.317

[15] Jurnal, R. (2019). Rancang Bangun Pemrograman Berbasis Sistem Cerdas Untuk Pengaturan Pengisian Batere Pembangkit Listrik Tenaga Surya. Energi \& Kelistrikan, 10(1), 1-14. https://doi.org/10.33322/energi.v10i1.316

[16] Batih, H. (2019). Estimasi Dampak Implementasi Kebijakan Terhadap Potensi Konservasi Energi Di Sektor Industri. Energi \& Kelistrikan, 11(1), 27-36. https://doi.org/10.33322/energi.v11i1.461

[17] Hasanah, A., Hariyati, R., \& Qosim, M. (2019). Konsep Fotovoltaik Terintegrasi On Grid dengan Gedung STT PLN. Energi \& Kelistrikan, 11(1), $17 \quad-26$. https://doi.org/10.33322/energi.v11i1.394

[18] Jurnal, R. (2019). Kajian Sistem Kinerja Plts Off-Grid 1 Kwp Di STT PLN. Energi \& Kelistrikan, 10(1), 38-44. https://doi.org/10.33322/energi.v10i1.322

[19] Siregar, R. R. A., \& Putri, D. R. (2017). Metode Support Vector Machine Pada Klasifikasi Audit Energi: Studi Kasus Gedung STT PLN Jakarta. Jurnal Informatika dan Komputasi, 8(2), 98-104. 